\title{
Secoiridoids from Dogwood (Cornus officinalis) \\ Potentiate Progesterone Signaling
}

Jung-Ho Lee, Julia R. Austin, Joanna E. Burdette, Brian T. Murphy*

Department of Pharmaceutical Sciences: Center for Biomolecular Sciences: College of Pharmacy, 833 S. Wood St., University of Illinois at Chicago, Chicago, IL 60612 United States

*To whom correspondence should be addressed: B.T. Murphy, Tel: (312) 413-9057, Fax: (314) 413-9303, E-mail: btmurphy@ uic.edu

\section{SUPPORTING INFORMATION (SI)}

Page SI2 Figure S1. The ${ }^{1} \mathrm{H}$ NMR (900 MHz, $\left.\mathrm{CD}_{3} \mathrm{OD}\right)$ spectrum of 1.

Page SI3 Figure S2. The ${ }^{13} \mathrm{C}$ DEPTQ NMR (225 MHz, $\left.\mathrm{CD}_{3} \mathrm{OD}\right)$ spectrum of 1

Page SI4 Figure S3. The $g \mathrm{HSQC}\left(900 \mathrm{MHz}, \mathrm{CD}_{3} \mathrm{OD}\right)$ spectrum of 1.

Page SI5 Figure S4. The $g \mathrm{HSQC}\left(900 \mathrm{MHz}, \mathrm{CD}_{3} \mathrm{OD}\right)$ spectrum of 1.

Page SI6 Figure S5. The $g \mathrm{HMBC}\left(900 \mathrm{MHz}, \mathrm{CD}_{3} \mathrm{OD}\right)$ spectrum of 1.

Page SI7 Figure S6. The ROESY (900 MHz, CD 3 OD) spectrum of 1.

Page SI8 Figure S7. Experimental ECD spectra of 1 and 2.

Page SI9 Figure S8. The PRE/Luc activity assay for the extract of dogwood fruit. 
Figure S1. The ${ }^{1} \mathrm{H}$ NMR (900 MHz, $\mathrm{CD}_{3} \mathrm{OD}$ ) spectrum of 1.

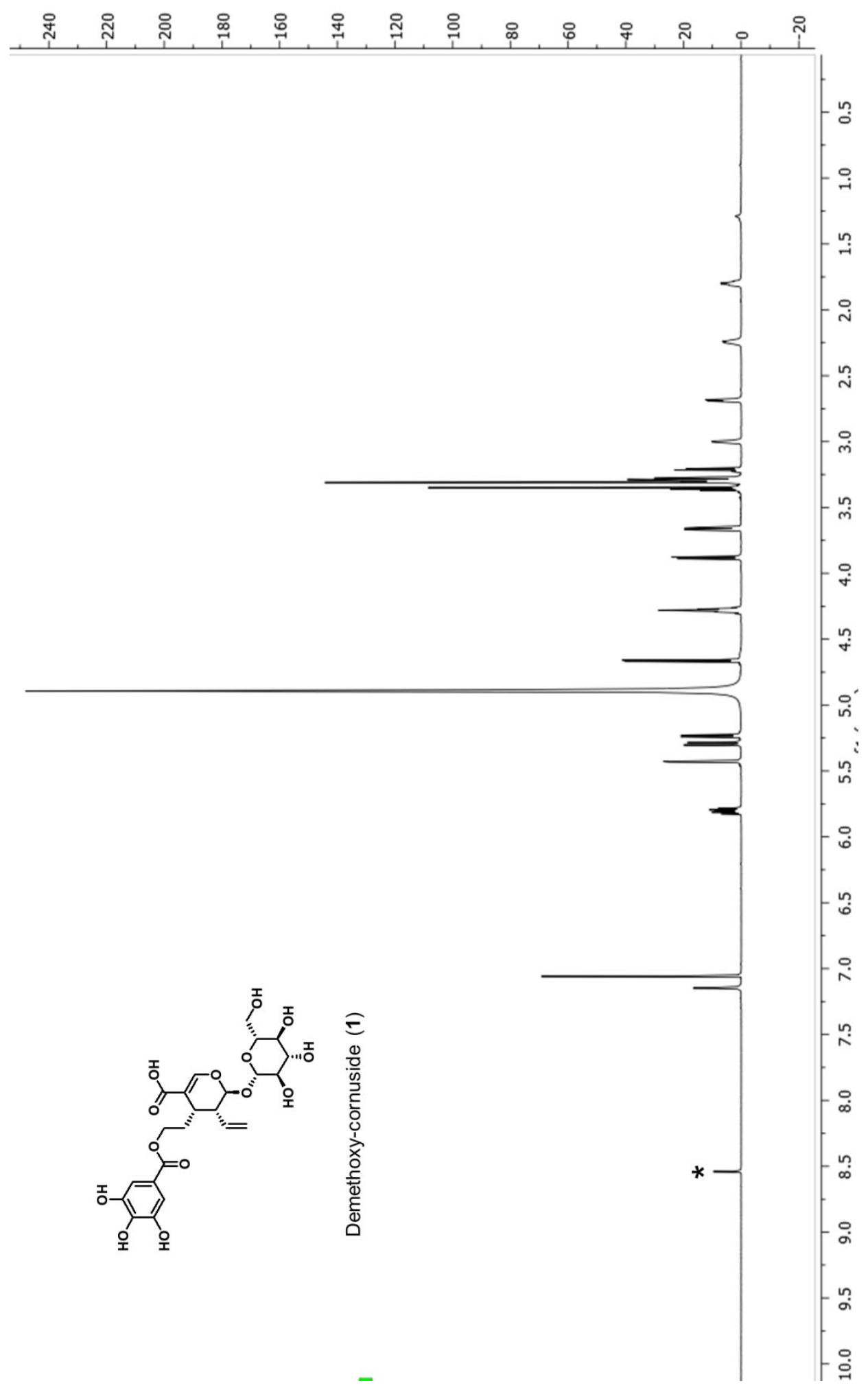

*Solvent impurities 


$$
\bar{F}
$$


Figure S3. The COSY (225 MHz, CD $\mathrm{CD}_{3} \mathrm{OD}$ ) spectrum of 1.

(wd) it

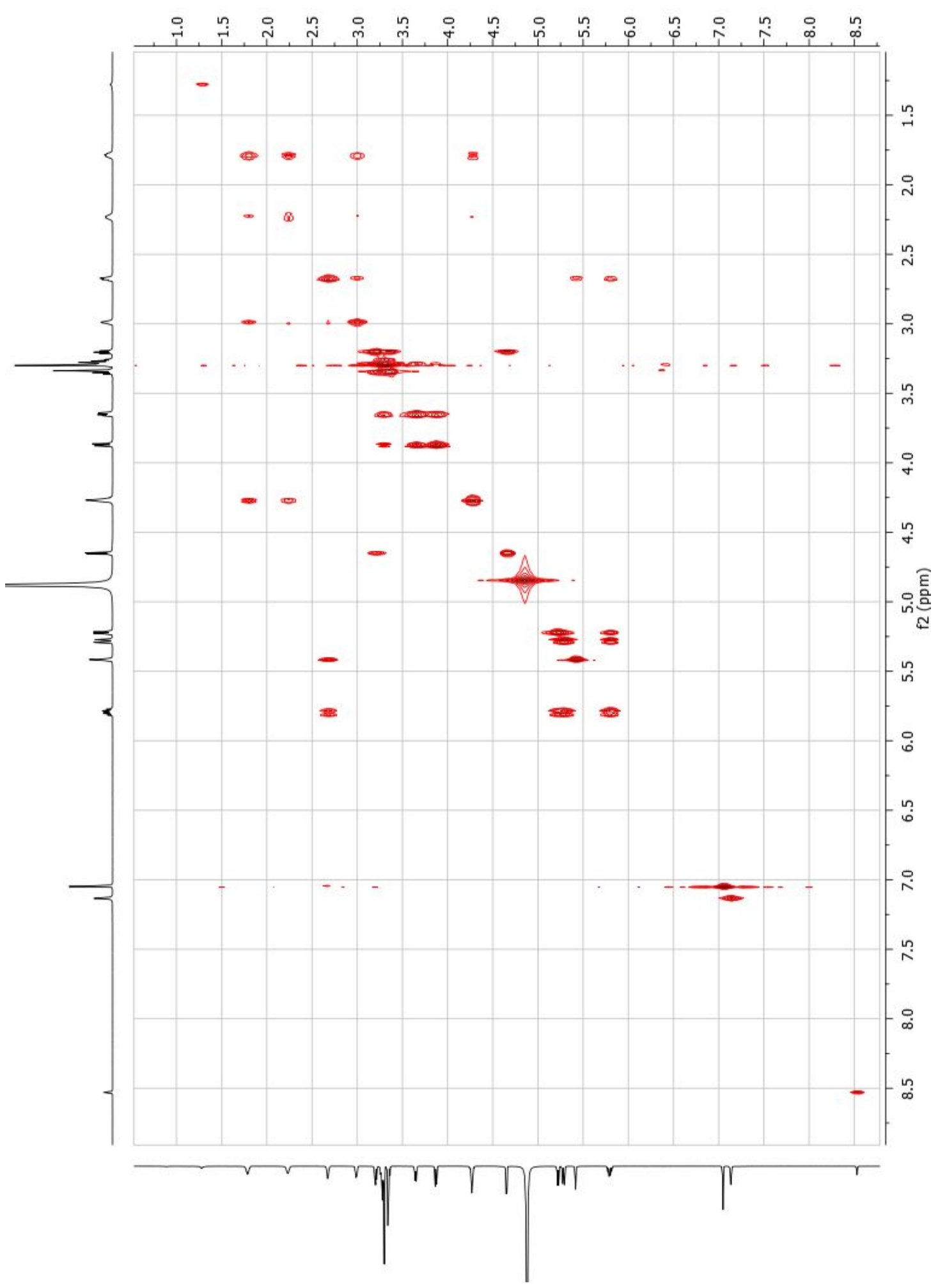

SI 
Figure S4. The $g \mathrm{HSQC}\left(900 \mathrm{MHz}, \mathrm{CD}_{3} \mathrm{OD}\right)$ spectrum of 1 .

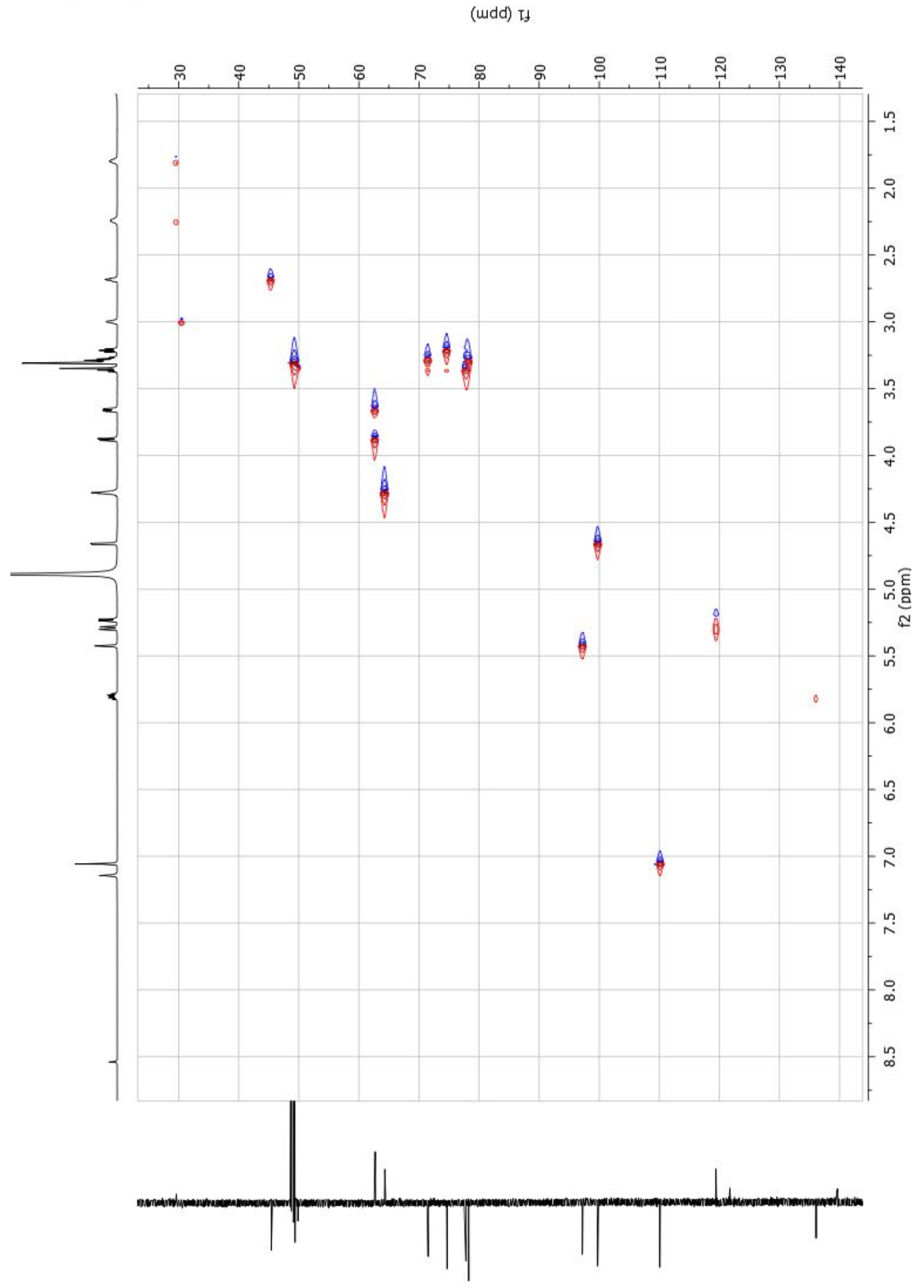


Figure S5. The $g \mathrm{HMBC}\left(900 \mathrm{MHz}, \mathrm{CD}_{3} \mathrm{OD}\right)$ spectrum of 1 .

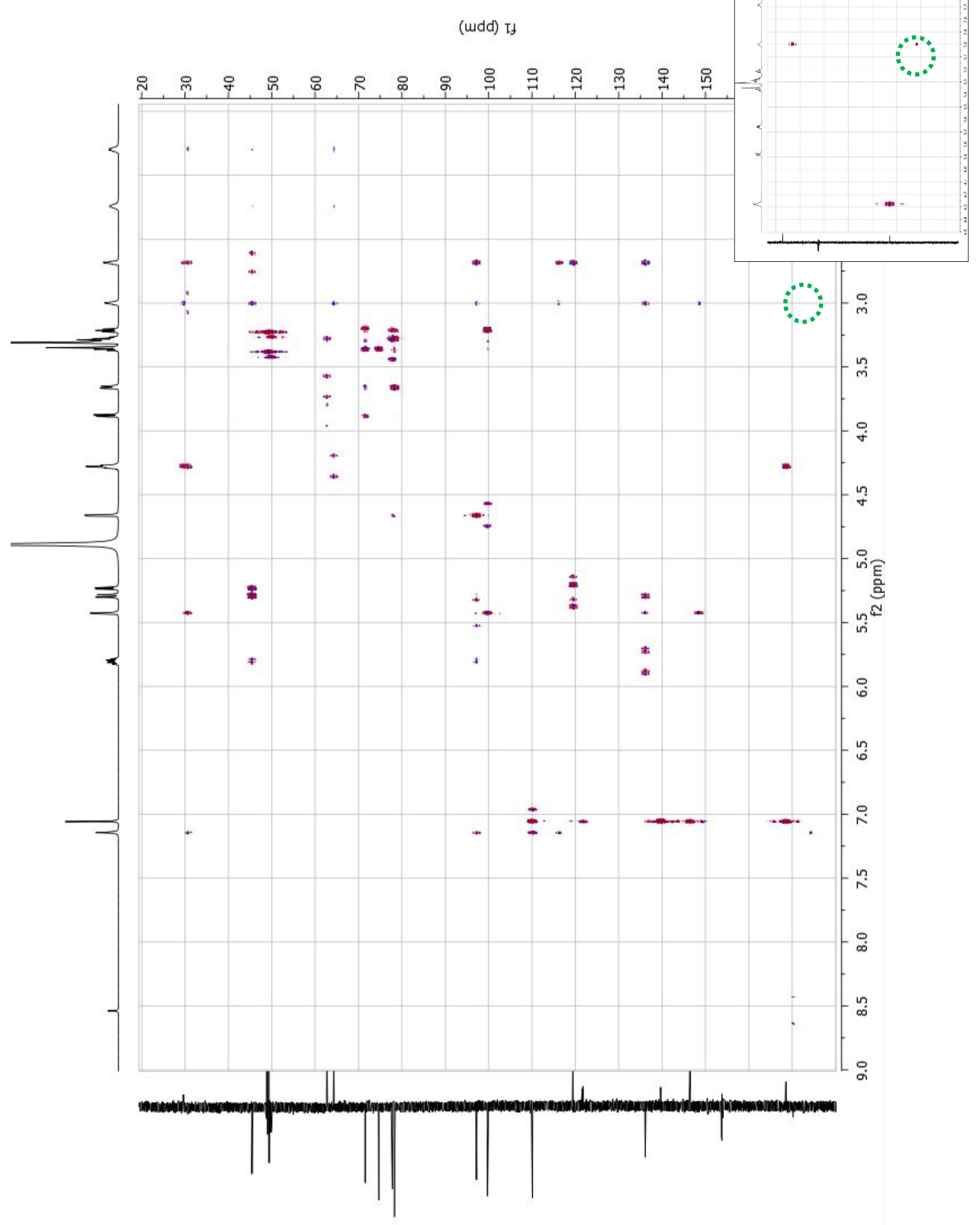


*Correlation between H-5 $\left(\delta_{\mathrm{H}} 3.00\right) / \mathrm{C}-11\left(\delta_{\mathrm{C}} 174.2\right)$ was observed in the higher contour level. Figure S6. The ROESY (900 MHz, CD 3 OD) spectrum of 1. 


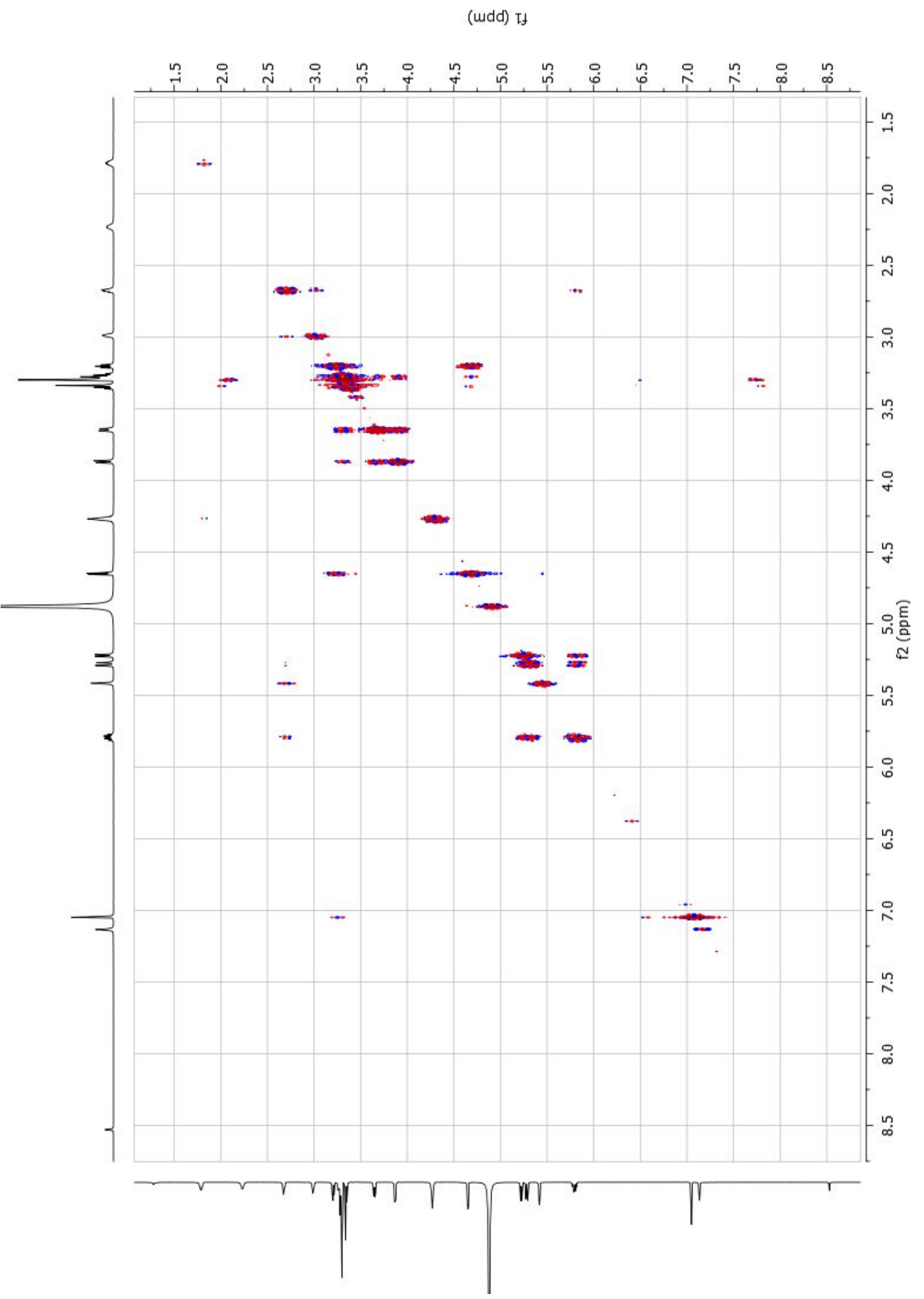

SI11 
Figure S7. Experimental ECD spectra of 1 and 2

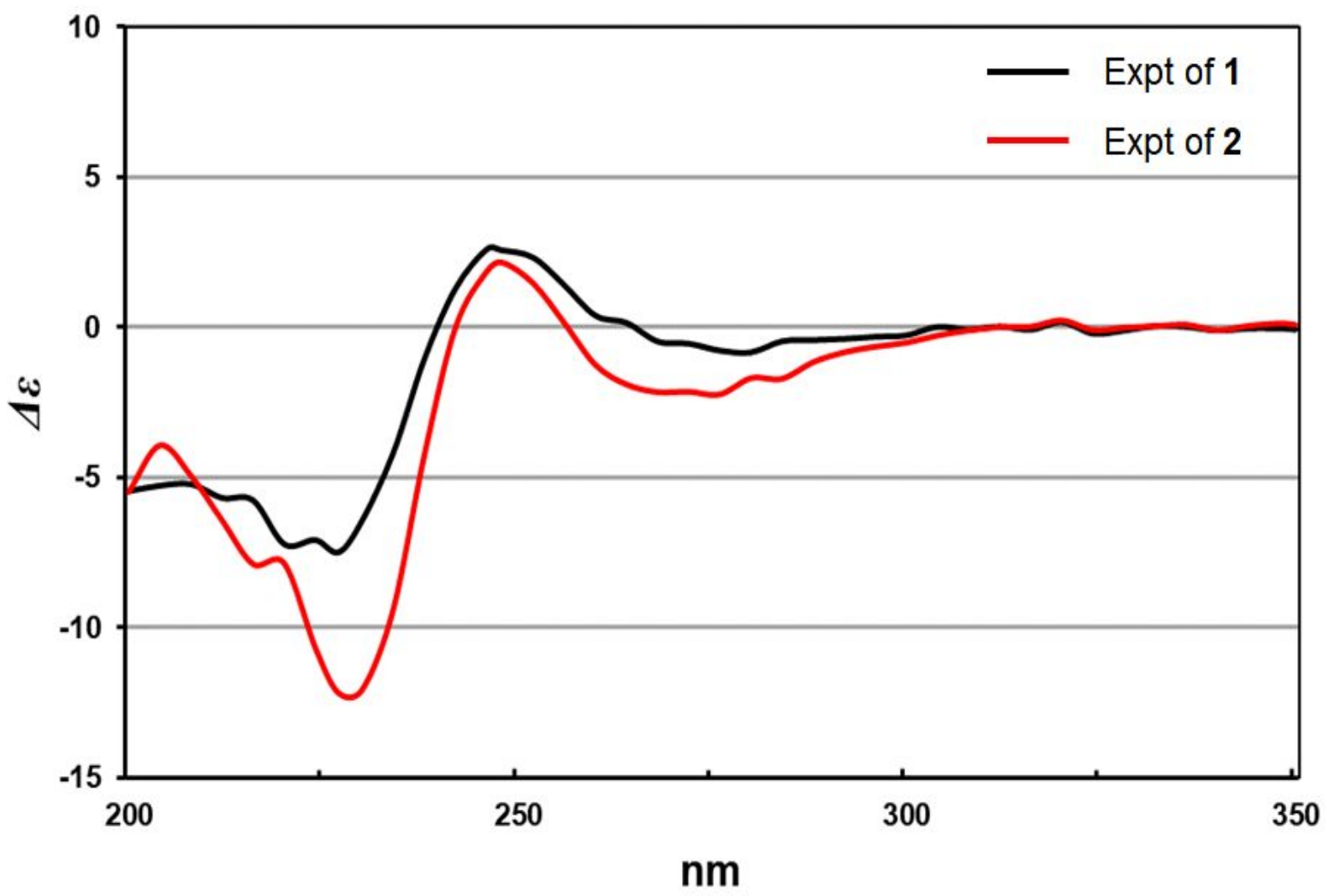


Figure S8. The PRE/Luc activity assay for the extract of dogwood fruit.

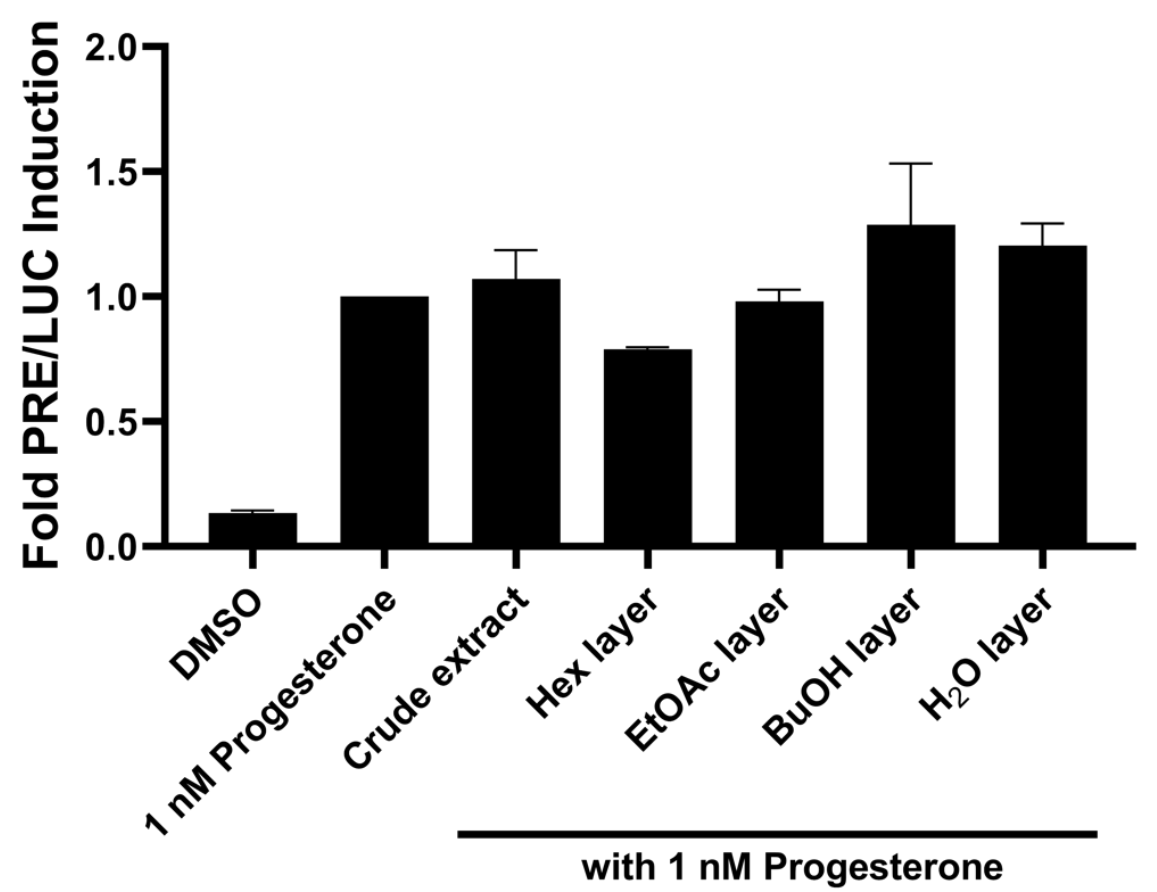

The extract of the fruit of $C$. officinalis did not potentiate progesterone signaling via

PRE/Luciferase. The hexane layer at $20 \mu \mathrm{g} / \mathrm{mL}$ exhibited antagonist activity with $1 \mathrm{nM}$ progesterone reducing PRE/Luc induction $21 \%$ compared to PRE/Luc activity for $1 \mathrm{nM}$ progesterone. $n=2$. Data represent mean \pm SEM. 